\title{
GRIDSHELLS: INTEGRATING DESIGN WITH STRUCTURAL PERFORMANCE IN EARLY DESIGN STAGES, USING FORMAL AND INFORMAL KNOWLEDGE
} GRIDSHELLS: INTEGRANDO PROJETO COM DESEMPENHO ESTRUTURAL, NAS
INICIAIS DE PROJETO, UTILIZANDO CONHECIMENTOS FORMAIS E INFORMAIS

\author{
Gonçalo Castro Henriques ${ }^{1}$, Juarez Moara Franco²
}

\begin{abstract}
:
Gridshell has long interested the enthusiast of lightweight construction. The most popular examples date back to the 1960s; gridshell development requires mathematical, technical and material resources. These requirements limit gridshell development to special buildings, and their design to specialists requiring considerable time and budget to construct them. Digital processes of design, fabrication and assembly offer renewed possibilities to tackle these difficulties and to deepen the interaction among form, material and structural performance. This article documents a didactic experience regarding architectural and engineering gridshell design aimed at relative beginners, considering structural behaviour from early design stages. The research is included in a broader research about gridshells that seeks to gradually integrate formal and informal knowledge about form-finding, including empirical and theoretical research. The didactic experience is framed in a series of empirical constructions we are developing, and contributing to the collective debate about how to expand gridshell construction further.
\end{abstract}

KEYWORDS: gridshell; strained, formal and informal design; Kangaroo; Karamba.

\section{RESUMO:}

As Gridshells há muito interessam os entusiastas em construção leve. Embora os exemplos mais conhecidos datem da década de 60; o desenvolvimento de gridshells requer recursos matemáticos, técnicos e materiais. Estes requisitos limitam o desenvolvimento de gridshells a edifícios especiais e seu projeto a especialistas, o que requer tempo e recursos consideráveis para os construir. Os processos digitais de design, fabricação e montagem oferecem possibilidades renovadas para enfrentar estas dificuldades e aprofundar a interação entre forma, material e desempenho estrutural. Este artigo documenta uma experiência didática sobre um projeto conjunto de arquitetura e engenharia sobre gridshells, voltado para iniciantes, considerando o comportamento estrutural desde os estágios iniciais de projeto. A pesquisa está incluída com uma investigação mais ampla sobre gridshells que busca integrar gradualmente o conhecimento formal e informal sobre formfinding, incluindo pesquisas empíricas e teóricas. A experiência didática está enquadrada em uma série de construções empíricas que estamos desenvolvendo, contribuindo para o debate coletivo sobre como expandir a construção de gridshells.

PALAVRAS-CHAVE: casca reticulada, métodos formais e Informais, Kangaroo, Karamba.
Fonte de Financiamento: FAU-UFRJ, FAPERJ, CNPq, PIBIC/UFRJ, PIBIAC/UFRJ.

Conflito de Interesse: Declara não haver.

Ética em Pesquisa: Declara não haver necessidade.

Submetido em: 23/03/2021 Aceito em: 17/08/2021 


\section{INTRODUCTION}

This paper describes a series of experiments that bridge Architecture and Structural Engineering in early design stages. In the process, we intend to "construct" a methodology, based on an iterative process of learning- by-doing, by testing physical possibilities and reflecting in order to map progressively the research field. Thus, the focus is not on a single solution to a problem, but rather on building and exchanging knowledge by testing solutions empirically to understand the solution space and to innovate. The article reports a didactic experience regarding architectural and engineering gridshell design addressed to relative beginners. We proposed a workshop as part of a broader research effort, aimed to integrate the creative processes in Architecture and Structural Engineering in a learning environment. This article presents some fundamental definitions about gridshells, architectural references that motivated this initiative, the theoretical and computational tools, results of this workshop and previous experience, and further developments. To understand the scope of this work, it is necessary to keep in mind the historical context of the professional training in architecture in the last two centuries, as well as the recent technological developments that have led to the transformation of these professional profiles.

The history of Architecture and Structural Engineering bears witness to an exciting exchange between theory and practice. However, the research developed in these disciplines tends to be autonomous in relation to one another, following different fundamentals, methods and goals, reinforced by the specialisation of architectural and engineering profiles induced by State apparatus at Ècoles Polytechniques and Ècoles de Beaux-Arts in France, since the 18th century. Unfortunately, different approaches toward tools, narratives and goals make it ever harder to exchange information between architectural and engineering teams. However, over the last few decades, technological developments have modified professional relationships in Architecture, Engineering and Construction (AEC). The improvement of personal computer power and the rise of interoperability for CAD and CAE systems offer new possibilities to integrate Architectural and Engineering Design. We can now integrate structural design in a continuous process, eroding the thresholds among specialists. We can use geometric information together with material properties in early design stages, on a common computational platform, saving time along and providing data accuracy. We argue that this methodology does not require architects to learn structural engineering in depth. On the contrary, it requires them to develop a new sensibility to use the knowledge and tools available to include structural information from early design stages.

LAMO-PROURB - The Laboratory of Models and Digital Fabrication of the Post-Graduate Program in Urbanism of the Faculty of Architecture and Urbanism of the Federal University of Rio de Janeiro - dedicates to the study of digital fabrication and its application to complex structures. It started a research about gridshells in partnership in the BRAGFOST - BrazilianGerman Frontiers of Science and Technology programme. To this partnership we invited the architect Tobias Wallisser to jointly conduct an experiment with us about gridshells to combine the German tradition with a Brazilian material, in this case bamboo, in a workshop in Rio de Janeiro (March, 2018). Our reference concerning gridshell techniques was that of Mannheim, developed by Frei Otto in 1975 . We challenged the participants to develop a bamboo gridshell, using the structural analysis tool Karamba3D (C) (a plug-in integrated in Rhinoceros (C) and Grasshopper (C) to assess the mechanical behaviour of the solutions. We also invited Professor Felipe Tavares (UFBA/UFPA) to interpret the mechanical results. Our first contact with gridshell in the Tropical Gridshell Experience was an empirical one, designing and building a pavilion at UFRJ in 2018 (Wallisser et al., 2019). This experience led us to understand the necessity to intensify the dialectic between theory and practice. This dialectic required the study of materials, processes and their constructive solutions. Regarding our pavilion, we were 
surprised to find Yuan (2018) had developed an alternative method to build a gridshell similar to the Tropical Gridshell based on Enneper we had built earlier. Yuan argues that some forms, like the one we developed for the Tropical Gridshell, are difficult to obtain as strained construction, as the assembly processes might limit certain geometries. As an alternative to overcome these geometric challenges, the author proposed a hybrid system to combine the advantages of pre-bent and bent parts in loco, in what we will describe further in our classification as strained and unstrained gridshells.

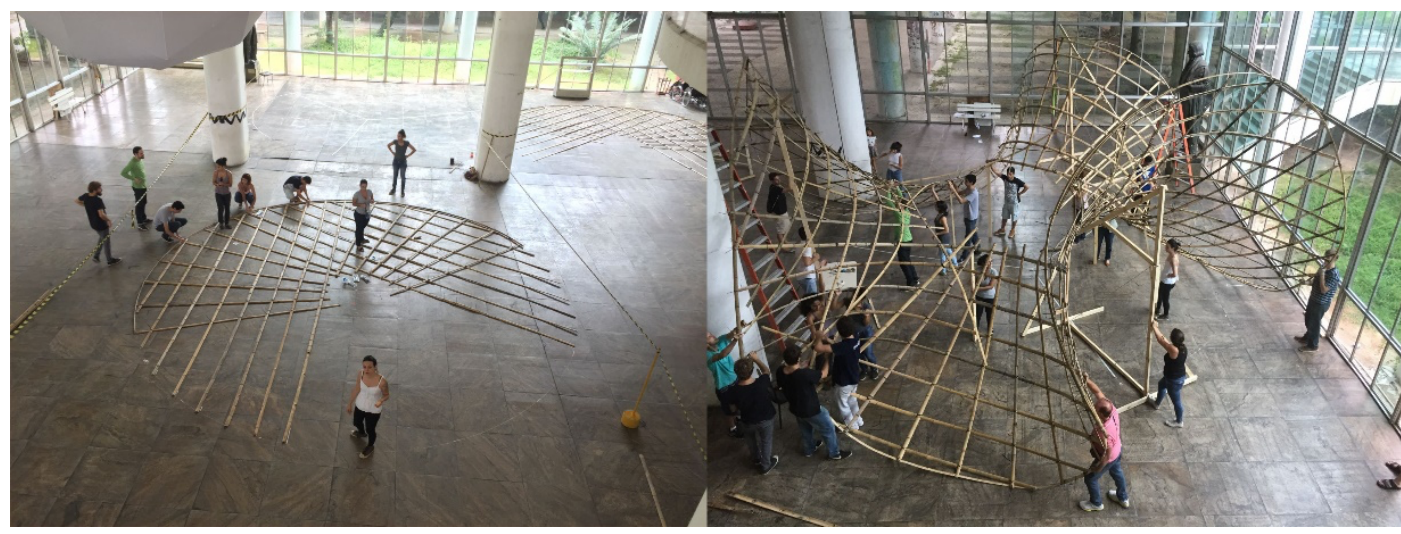

The research continued in Germany, where the study investigated for analogies between gridshells and the typology of the OCAs - traditional indigenous constructions in the Amazon rainforest - in a joint workshop with the structural analysis conducted by Thomaz Vieira (PhD student at Detmold University). Both design workshops used physical and parametric models, but we only accessed the structural performance in a late stage of development, prior to the final construction. The difficulties in predicting the results in an earlier stage encouraged us to include structural calculations in the initial design stages. Professor Juarez Franco (LOGIFABUFRRJ) was invited to act as a consultant to improve the Tropical Gridshell construction results that presented challenges to solve. More recently, the authors of this article joined forces to prescribe general guidelines to co-ordinate form-finding with structural analyses in the workshop, "Mutable Surfaces" (2020). In this process, we introduced the participants to a basic knowledge of structural analysis. The methodology developed included shape dynamic relaxation (Kangaroo) and structural analyses regarding internal forces, displacements and buckling (Karamba3D). The results also encouraged reflection on how to integrate the formal and informal processes we shall describe.

\section{INTEGRATING FORMAL AND INFORMAL KNOWLEDGE}

According to Mitchell (2008), the construction of computational environments for Architecture is based on three principles: (i) access to knowledge about good construction practices, which must be suitable for "grammatical formalisation"; (ii) grammatical formalism that is a prerequisite for definition of "design worlds"; and (iii) establishment of design worlds required for creation of design languages in a computational environment. This robust framework depends on the availability of formalised (codified) knowledge about building construction, which may not be trivial. For example, there are creative processes in architecture (nonformalised knowledge) and innovative environments in engineering (knowledge subject to formalisation, but not yet available). This study corresponds to a period before the principles proposed by Mitchell, when the focus was on the preliminary understanding of the properties of a constructive system, addressed to future, more robust computational implementations. Clearly, the first step is a definition of such "formalised" and "non-formalised knowledge" (Alexander, 1963).
Figure 1. Tropical Gridshell experience, BRAGFOST Brazilian German Frontiers of Science and Technology support Von Humboldt DAAD, co-ordination Gonçalo Castro Henrique and Tobias Wallisser with Daniel Lenz, Rio March 2018.

Source: authors / LAMOPROURB 
We use the term "informal knowledge" to refer to the non-explicit knowledge used to build with a certain material, according to a technique, improved by trial and error. Weaving is an ancestral process of interlacing threads, an example of informal knowledge like other techniques and materials, such as carpentry and wood, stereotomy and stonework, or forging and metal (Semper, 2004). To build is to make the best use of the individual characteristics of each material, so that the parts assembled as a whole exceed the sum of the properties of the individual parts. We might access this type of knowledge by implicit or intuitive traditional methods. For instance, to tessellate a surface is to divide it into smaller "tessellas", without voids. A "tessella" is a word that comes from Latin, referring to a small piece used by artisans to fill cover a surface with a certain material. A good tessellation requires consideration of the composition, material, assembly and the aesthetic values holistically. Artisans transmit this know-how verbally from generation to generation. Alexander (1963) designates this type of knowledge as unconscious or non-formalised.

Architects seek to improve form in a continuous process. In this search, they often deal with wicked problems requiring decision-making without a pre-established algorithmic process (Buchanan, 2006). The nature of these problems encompasses a wide range of possible solutions and often includes subjective factors, leading to resort to heuristic methods based on empirical experience in the design process. The literature on Architecture designates formfinding in a broad sense, including both the search for form using computational algorithms, as well as informal knowledge, without the methods to "optimise" the form in a mathematical sense, as in engineering. In this work, we adopt formal and informal knowledge to differentiate decision-making processes based on explicit computational methods and processes using noncoded knowledge - such as the implicit knowledge referred to above. Formal processes have explicit computational definitions, which Alexander associates with self-conscious practice. On the other hand, informal knowledge originates from the empirical craftsmen's trial-and-error, which eventually neither draws nor calculates, but includes intuitive factors that are not always quantifiable or computable, despite resulting in an evolution of solutions for generations. As mentioned in the literature about gridshells (Toussaint, 2007), the design of this type of structure is the art of bringing together the perspectives of architecture and structural engineering to achieve a solution where the criteria of both fields of knowledge converge in an elegant way.

Before computers, to conduct form-finding we had to use analogic processes, such as the suspended chain method adopted by Gaudí and the builders' guilds since the medieval period. On the other hand, we might resort to informal knowledge that is not optimisation in the strict structural sense. This research seeks to reconcile formal and informal knowledge (implicit and explicit processes). We do this in two ways: one is by automating processes not codified before, and the other by understanding how to work with processes that we cannot encode - that we might incorporate intuitively. Therefore, the goal is not to achieve the best possible solution, but rather to find feasible solutions according to a variety of parameters and objectives, some of which are more difficult to evaluate in the manufacturing and assembly processes. We describe a research that is closer to a top-down process, where the architecture and structures team develops the basic project of the "form as a whole", in parallel deepening the assembly and constructive detailing stages. In a bottom-up process, the architecture-structure team can start by restricting the set of basic building elements and structural elements, defining a constrained generative system, that is, restricted a priori to, for example, the manufacturing and assembly options.

On other hand, computational implementation - related to geometry, simulation and the construction processes - requires formalised information about building materials and techniques. We can integrate a computational technique into the concept of tessellation: the 
discretisation of three-dimensional surfaces. By discretising a surface, we can access its parametric space and topology. However, the discretisation, in a strict mathematical sense, although useful, might not include compositional intuition, which is part of the know-how used to build according to the unconscious building tradition. Incorporating intuition is important, for example, for architects to access complex information they do not know how to encode. Another relevant aspect to consider in a tessellation is the manufacturing and assembly techniques used. Lienhard et al., 2013 reviewed the use of strained structural elements (designated by the Lienhard as active bending) from the ancestral intuitive processes of building associated to each culture. In the 20th century, they associated the incorporation of analogical processes, of the type, "the form follows the physical forces" with Gaudí, Fuller and Otto, which, later, were extended via the numerical computational processes, merging aesthetics with structural performance.

The gridshell design process requires integration between aesthetic and structural knowledge. As others, the structural project is organised into four steps: (i) "conceptual design" to define shapes and aesthetic intentions; (ii) "pre-sizing" to assign initial sizes to the structure based on empirical knowledge; (iii) "structural analysis" to evaluate significant physical phenomena; and (iv) "structural design" to evaluate safety criteria. In this task distribution, the architectural team is normally responsible for "non-formalised knowledge" in steps (i) and (ii). On the other hand, the engineering team are responsible for the "formalised knowledge" in steps (iii) and (iv). This serial process is not linear. To obtain an integrated design that includes form and materials, it is desirable to have a parallel decision process between architecture and engineering to achieve synchronic and efficient designs, from both the aesthetical and mechanical points of view. This parallel synchronisation should reduce time, waste and rework due to miscommunication between teams.

\section{DEFINITION OF ELEMENTS, SYSTEMS AND STRUCTURAL VARIABLES}

This article reports a didactic experience addressing a relatively beginner audience, using different terms in an equivalent manner. In this context, a frame, a mesh or lattice shell is essentially a shell structure composed of bar elements, in a relatively slender surface, when considering the total dimension of a structure. In the structural engineering literature, the term "truss" is a particular case of a framed structure, where the bar elements are not subjected to flexural bending moments, neither shear forces. On the other hand, a strained gridshell is a curved structural surface constituted of flexible bars elements, bent in situ. We combine these elements in a flat mesh that we deform or "curve" during the process of assemblage. The curvature introduces flexural bending moments in the reticulated shell. The non-strained reticulated shell, on the other hand, is a curved and reticulated structural surface, where the bars acquire their shape in the manufacture process (so it is the opposite of the process of the strained reticulated shell, which acquires its shape during the assemblage). For structural engineering, a "bar element" has a dimension (axis) much larger than the other two (sections), while the "shell element" has two dimensions greater than the third (thickness). The reticulated shells, for combining these two systems with distinct characteristics, belong to a special class of structures. If we consider that their connections are pinned, we should get hypostatic systems; however, even if their connections are rigid, it is possible to result in systems with relatively low stiffness in the normal direction to the surface (by definition, structures with low rigidity present a large displacement when subjected to unitary loads, and it compromises their integrity). As it turns out, gridshells presents some special characteristics and difficulties. In order to start a systematic investigation, a useful strategy is to divide designs geometric parameters on three "classes": (i) "shape variables", that relate proportion between the structural system and its parts, (ii) "size variables", associated with the size of bars cross sections and (iii) "topological variables", which relate to the adjacency relationship between 
the bars. Finally, "sensitivity analysis" is the technique used to relate each variable on shape, size and topology classes to any significant structural mechanical behavior. Sensitivity analysis is an engineering strategy that returns the "degree of freedom" for architectural team: what are the constraints of each project? What can architects decide inside these limits, without waste? Only a parametric, CAAD/CAE integrated process can offer this kind of approach.

It is usual for architecture to account for formal and topological variables and for engineers to make decisions regarding dimensional variables. This division, however, depends on the type of project, the degree of integration between the teams and the tools they share. The integration of computational architectural Design (CAAD) and engineer (CAE) tools allows the stages of conceptual design, pre-sizing, structural analysis and structural design in synchronous deployment, that is, for teams to work in parallel, on a common computer platform. It is thus fundamental to understand the classes of variables, objectives and strategies of the project with gridshells to develop an integrated computational design.

There are many different parametric design approaches and others approaches to combine CAAD/CAE strategies on a structural design. There is full automation process, semi-automatic process and full human-based decisions processes. We can achieve solutions by using different strategies, all of then based on shape, size or topological variables. From a performance point of view, it is possible to define objective and subjective goals to a product. In this research, we could only fully automate the objective goals (engineering). Side-by-side with many others artificial intelligence approaches, "numerical optimization methods" they require one or more objective goals and objective constraints to maximize the system performance. On other hand, a semi-automatic approach demands objective constraints and allows human-based, subjective decisions. As it turns out, there is no "best" way to integrate CAAD/CAE/IA the architectural/engineering design process. All we have are multiple possible strategies and a large investigation field to explore.

Before computers, to do form finding we had to use analogue processes, such as the suspended chain method adopted by Gaudí and the builders guilds since the medieval period. On the other hand, we use informal processes that are not optimization in the strict structural sense, as it will explained in the process description. This research seeks to reconcile formal and informal processes (implicit and explicit processes). We do this in two ways: one is by automatizing processes that we did not codified before, and the other is by understanding how to work with processes that we cannot codified - that can be incorporated intuitively. Therefore, the goal is not to achieve the best possible solution, but rather feasible solutions according to a variety of parameters and objectives; and some of them are more difficult to quantify, as the manufacture and assembly processes. We describe a research that is closer to a top-down process, where the architecture and structures team develops the base project of the "form as a whole", deepening in parallel the stages of assembly and constructive detailing. In a bottom-up process, the architecture-structure team can start by restricting the set of basic building elements and of the structural elements, defining a constrained generative system, that is, a generative system restricted a priori, for example, the manufacture and assemblage options. With integrated CAAD-CAE-CAM systems, it is possible to include both strategies.

Charest et al. have analysed examples since the 1960s, identifying two constructive types, elastic and rigid gridshells, raising the fundamental question of how to obtain the final shape of the structure. In accordance with other authors (Adriaenssens et al., 2014), we believe that it is more appropriate to differentiate strained gridshells (that is, under tension) from unstrained gridshells (that is, not under tension), so we adopt this gridshell classification in our article. 

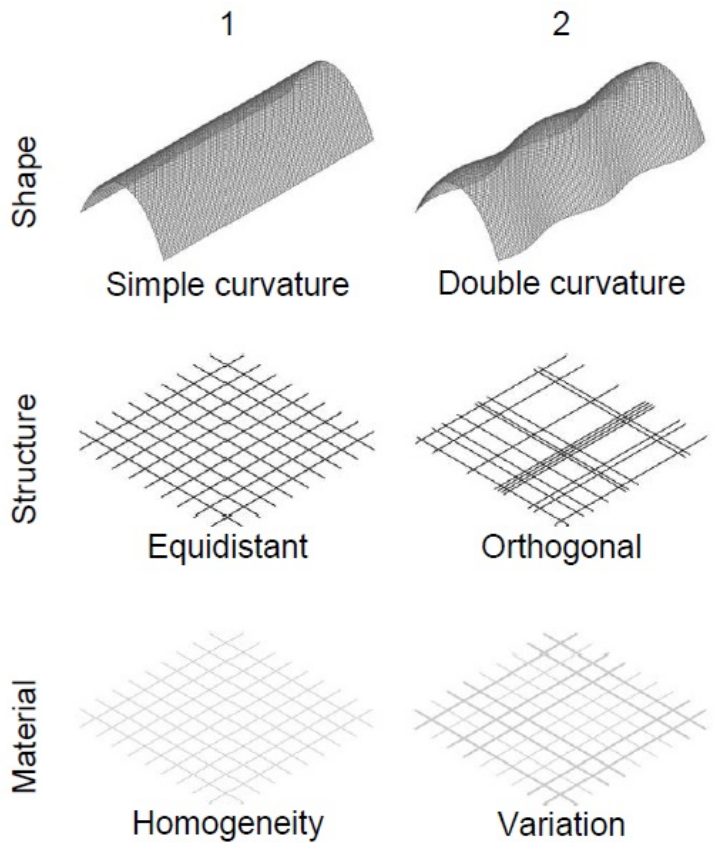

Variation
3
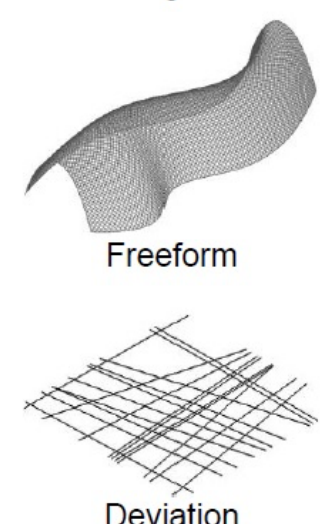

Deviation

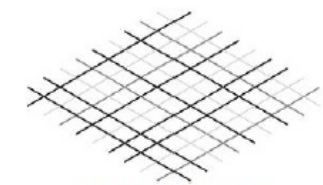

Heterogeneity
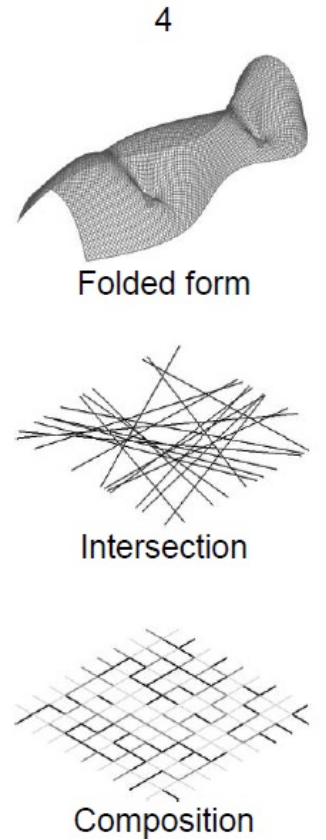

In the late 80s, upon the advent of computational methods, strained gridshells became popular, a trend that intensified in the late 90 s with the popularisation of digital manufacturing processes. Strained and unstrained processes might present different advantages to obtain the final form. An alternative to simplify the construction of gridshells might be to combine both processes. However, further research is needed to find out how to simplify these processes, resorting to new materials and processes to expand the geometric possibilities. The authors assume that to improve it is crucial to include structural analysis, even with low resolution, from the very beginning of the design process, introducing in the form-finding process, interaction between the geometry, loads and material properties.

An issue that has a direct impact on gridshells is the relationship between the materials and the construction scheme used (Fernandes et al., 2016). This author classified strained gridshells into 3 types: compression (arches), tension (catenary) and irregular or mixed gridshells. This was a simplified classification, as a gridshell can present a part of the bar elements under tension, and another under compression. He also mentioned that the construction can use the methods: pull-up (hoisting upwards with a crane); push-up (pushing from below, for example, with actuators); ease-down (suspension from above to acquire the form); and inflation (inflatable filling). A recent Ph.D. thesis, for instance, developed and built a pneumatic tension gridshell (Quinn \& Gengnagel, 2014). The researcher studied and documented the form-find and assembly processes used. It also refers to diverse mathematical form-finding techniques for gridshells as suspended chains, the Chebyshev network, or the compass method. Finally, the work of Quinn \& Gengnagel (2014) summarises the assembly processes and construction in reference pavilions. 


\section{OVERVIEW OF EXISTING GRIDSHELL PROJECTS}

In this section, we present a brief survey of built gridshells, reflecting on their characteristics, relevance, and with reference to our classification of strained and unstrained gridshells. Although the invention of gridshell is attributed to Shukhov because of the metallic structure featured in the Vyksa Pavilion in 1896, the founding example is the Multihalle Mannheim, designed by Frei Otto in 1975, due to its wide spatial span and lightweight double-layer of strained wood. After this construction, in 1991, the EPFL Polydôme used the same principles in a strained process. Subsequently, sometimes it was necessary before new buildings emerged using the original technique by Frei Otto, due to the complexity of calculation and the building process. Shigeru Ban. with Frei Otto, developed an interesting experiment in the Japanese Pavilion in Hanover, in 2000. Regarding the development of strained gridshells, we must mention Happold's Weald and Downland museum in 2002 and Howells' Savill Garden Pavilion in 2006. Both used advanced technologies to produce structures under tension, following Otto's tradition. However, these solutions remain complex, time-consuming and costly. We can see the influence of digital manufacture in the last few decades in a set of projects with strained gridshells, with laminated wood, such as the Center Pompidou-Metz and Nine Bridges Country Club of Shigeru Ban in 2008 and 2009, respectively, as well as the well-known Metropol Parasol by Mayer in 2010. In the last two cases mentioned, the structure acquired its shape during the manufacturing process, which, although more complex, avoided additional stress forces during assembly.

Figure 3. Strained Gridshell built of curved wooden laths, the smart geometry gridshell and the Ongreening gridshell, more info Cabrinha (2014) e Harding (2014)..

Source: Public Domain photos, edited by the authors.

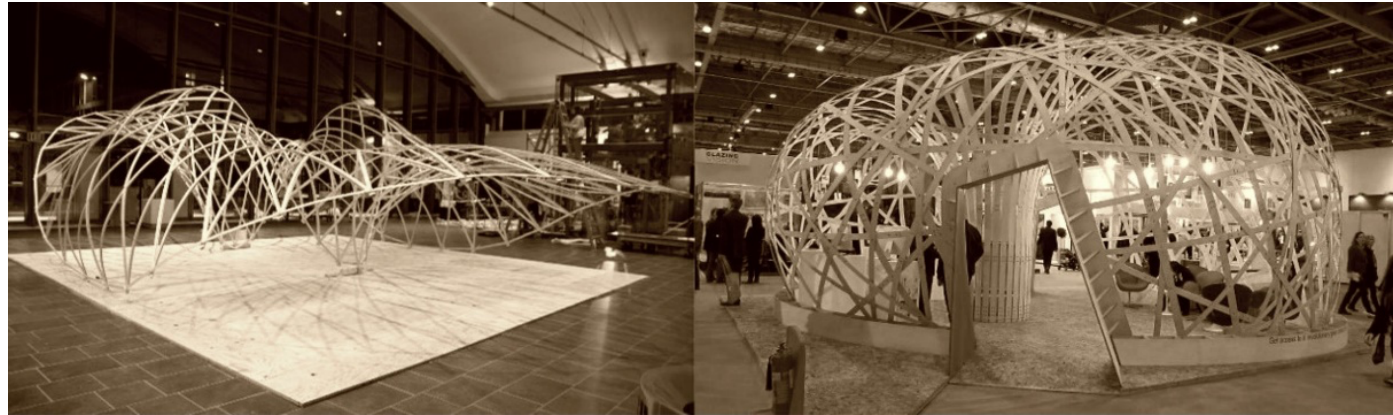

The complexity of manufacture might explain the renewed interest in strained gridshells, rethinking geometric and material properties, developing new approaches, such as in the Solidays' Festival Pavilion in 2011, which used GRFC tubes (Tayeb et al., 2013), and other solutions that used wooden slabs, such as the Smart Geometry Gridshell in 2012 (Cabrinha, 2014) or the Almond Pavilion in 2012 (Soriano, 2017). Other examples explore dynamic relaxation to simulate and discretise strained gridshells, such as the ZA Pavilion (Naicu et al., 2014) or the Toledo gridshell 2.0 (D'Amico, 2014) developing digital form-finding, also used to produce modular systems with digital fabrication (Mork et al., 2016).

The construction of pavilions under tension introduces important loads in the assembly process in double-layered grid systems. There are recent examples of strained gridshells that attempt to simplify the process. It is the case of several academic experiments, such as the one at Chalmers University (Adiels et al., 2017) or at the University of West London (Harding, 2016), developed in collaboration with mathematician Chris Williams, or the Ongreening Pavilion (Harding et al., 2016) (figure 3); trials alternative solutions were performed in Spain by González and Pastor (2019). As examples of the development of strained gridshells, there are also some examples in academia, using digital fabrication and meshes, such as the Catalyst Hexshell projects (Kudless, 2012) and the Pavilion Mesh-gridshell (Naboni, 2016). 


\section{WORKSHOP MUTABLE SURFACES}

The universities UFRJ (Brazil), Bio-Bio (Chile), UNL (Argentina) and UCR (Costa Rica) jointly organised the Seminar/Workshop, "Mutable Surfaces", held in Rio de Janeiro from $9^{\text {th }}$ to $16^{\text {th }}$ February 2020, addressing different exercises regarding fabrication of structures, each university sharing previous experiences. Andres Passaro, Pedro Engel, Daniel Lenz and Gonçalo Castro Henriques co-ordinated the event with the LAMO-PROURB team, along with the collaboration of the guest professors: Rodrigo Alvarado, Mauro Chiarella, Carolina Vargas and Juarez Franco. Moreover, Alexis Salinas, Paula Ochoa, Luciana Gronda, Martín Veizaga and Gonçalo Castro Henriques participated as external tutors, along with other participants from different countries.

During this workshop, the authors of this article conducted an exercise to design a structure with performance evaluation. The tutorials of that project associated parametric design and structural analysis in real time, using the Finite Element Method (FEM) in Grasshopper with the Karamba3D plug-in (Preisinger, 2013). We challenged the participants to develop a feedback process, associating the design characteristics of a surface - defining the grid pattern, namely its density, direction and dimension, developing different proposals - and finally to compare and evaluate the different proposals according to their behaviour and structural performance. For structural simulation, we chose the software Karamba3D because it allows expeditious, real-time interaction instead of a high-precision analysis, which takes longer and is reserved for specialists. We explained different points of view about the proposals' expected performances while explaining the conception algorithm. When considering Architecture and Engineering principles at the same time, the best architectural solution may not be the most resistant or the most rigid, but we must not violate safety restrictions. To guide the formfinding process, we used formal and informal knowledge, meeting technical and aesthetic requirements, as well as numerical results that ensured adequate structural performance. The solutions combined digital methods with physical test models that allowed testing beyond the stability, the type of connections and the assembly sequence.

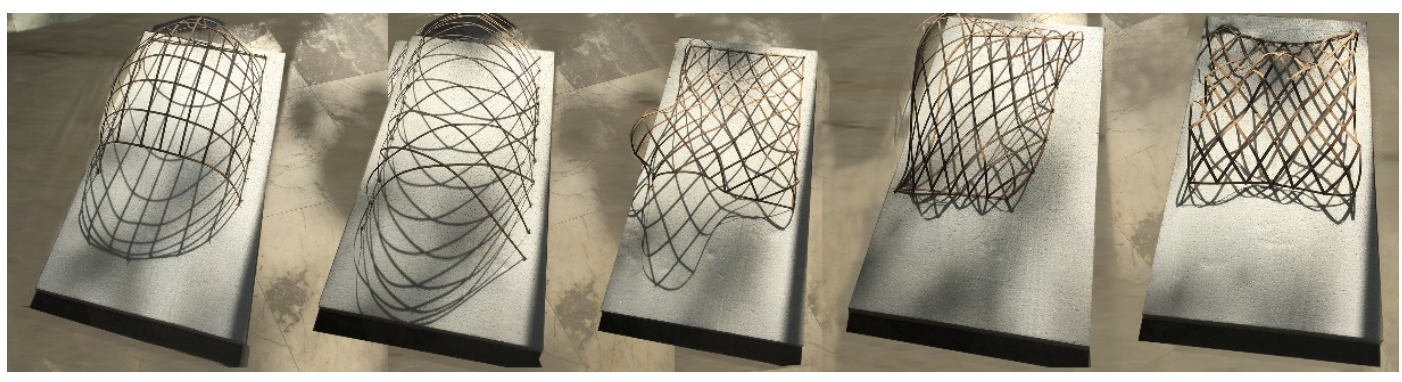

To develop a gridshell, we introduced participants to visual programming and structural analysis, including, from the beginning, formal, material and processual thinking. We applied a type of problem and proposed a methodology to design a structure in a space of $6 \times 4 \mathrm{~m}$ (laser cutting area, at a $1 / 10$ scale). The participants started by modelling a flat NURBS surface on the ground. They then modelled a 3D surface by manipulating the control points of the surface, defining the position and number of supports - for example, along the entire perimeter, supported on one, two, or three sides and on specific supports. They developed different types of surfaces. Through this simple process, they modelled a continuous NURBS surface, and tessellated this surface using regular grids, diagrids and geodesic grids. They developed the design with the FEM analysis, taking into consideration the construction and material processes (Figure 4). The workshop included other exercises, developed by different tutors, including experiments with form-finding in Kangaroo (Piker, 2013), based on previous
Figure 4. Physical gridshell models developed during "The Mutable Surfaces" workshop, UFRJ 2020.

Source: authors / LAMOPROURB. 
experience (Chiarella et al., 2019). After the workshop, in the current pandemic scenario, LAMO-PROURB organised a group to continue the research online. Due to the situation, we had to use only digital processes.

We proposed development of these gridshells using cardboard manufactured in a laser cutter, using the maximum dimensions of $80 \times 40 \times 0.3 \mathrm{~cm}$, at a $1 / 10$ scale. In order to evaluate performance, we considered self-weight load, displacement, buckling and the structure's utilisation rate. Every structural system must offer enough stiffness to self-support, or, in other words, presenting minor displacements within an acceptable value to avoid collapse. Brazil has standards for many 'types' of structures, but none of them is applicable to our small-scale cardboard mockups. As a didactic approach, this study adopted the philosophy of the Limit State Design (LSD), which assumes a set of displacement checks (Serviceability Limit State SLS) and another for strength (Ultimate Limit State - ULS). The SLS indicates whether, or not, any point of the structure has a displacement greater than the reference value, $\delta_{\text {adm; }}$ the ULS, requires that no action $S$ (normal force, shear force and moments force) be greater than the strength $\mathrm{R}$ of the components or the structural system as a whole. The utilisation rate $t_{\mathrm{x}}$ is defined by the $S / R$ ratio. Using the rate $t_{x}=1$ means that internal forces are equal to the structural strength; $t_{x}>1$ ensures that internal forces have exceeded strength capacity and that the structure will surely collapse; $t_{x}<1$ gives us a reasonable assumption that the structure is safe.

Brazilian standards establish nominal and design values of strength using safety factors, but, once again, we could not apply them to a cardboard mockup. As a first approximation, and with the purpose of offering initial contact with structural analysis for beginners, we adopted exaggerated generic safety factors. We imposed that: (i) no structure should present a displacement greater than $1 / 200$ of the smallest support span; (ii) the rate of utilisation should not exceed 0.90 ( $90 \%$ use) when considering the bars separately; and we adopted a safety factor equal to 3 for the behaviour of the system as a whole (load factor obtained by a buckling analysis result greater than 3). Unfortunately, the algorithms based on different international standards, implemented in Karamba3D, have limited application in undergraduate teaching, even for this simplified, didactic approach. The exercise proposed for the workshop was just a first approach to CAAD/CAE/CAM interfaces for beginners, and their simplified results to serve as general design guidelines.

\section{RESEARCH AFTER THE WORKSHOP}

The research after the workshop continued by collecting gridshell examples from articles, books and theses, as summarised in the previous section of this article. In addition to the aspects mentioned above, we analysed the computational form-finding and performance tests used to develop these projects. With this theoretical and practical research, combined with the results of previous workshops, we started to envision how to design the research process to develop further solutions. We used a form-finding process organised into 4 steps, described as follows: 1- Design of a flat surface defining a set of anchor points, and then applying forces with dynamic relaxation in Kangaroo to obtain a deformed mesh; 2-Translation and redesign of the previous mesh to obtain a continuous NURBS surface. Using the surfaces, we could extract different grids from the surface, such as isocurves, geodesic contour curves, and others, to generate the gridshells; 3- Evaluation of the set of solutions developed with FEM analysis; and 
4- Selection of the final nurb surface and the best grid for this surface considering the factors mentioned. We summarise this iterative process in Figure 5.

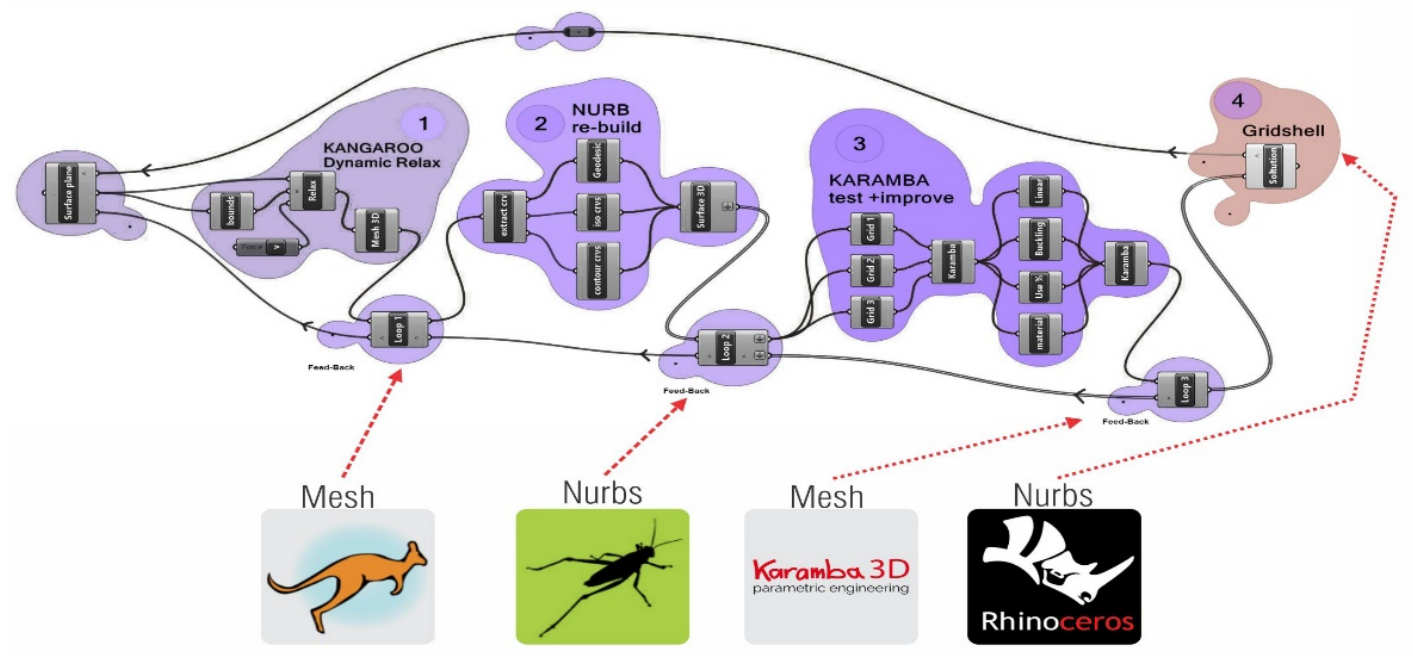

Figure 5. Iterative design process, symbolic representation in visual programming with Grasshopper, including feedback: 1- Dynamic relaxation (Kangaroo), 2Mesh to Nurbs, 3- NURBS to 2D curves and FEM Analysis (Karamba) 4- Nurbs result..

Source: authors / LAMOPROURB.
In the form-finding process, we used dynamic relaxation in Kangaroo version 1 to obtain an initial mesh-type solution, described in the previous diagram. The participants explored more complex shapes than the previous ones, which included topological discontinuities - such as one, two or three holes - and tested the supports more actively. In this process, the shape of the polygonal mesh resulted from the interaction of the flat mesh, with applied forces and the support points, considering basic material properties. To use the polygonal meshes obtained in the Kangaroo for creating a gridshell, we need to work on the information provided, as the meshes are elements separated into parts, and do not have the topological continuity of the NURB curves and surfaces. If we used the mesh points directly, their mathematical order would be different from that necessary to create curves and surfaces. Therefore, it is fundamental to re-order the information to create interpolated curves, which requires intensive reorganisation of the point lists.

Therefore, the process took place using the points to recreate topologically continuous surfaces, which forced us to go back frequently and modify the original mesh, or to change its supports, in a feedback process. Once we had defined the NURBS surface, we extracted several types of curves, such as isocurves, contour curves (in $\mathrm{x}, \mathrm{y}$ or $\mathrm{z}$ ), for example), and geodesic curves. To reconstruct the meshes, especially due to the discontinuities of the holes, it was important to use mesh-sorting methods - that is currently a wide field of computational research - to reorganise the meshes according to mathematical criteria. At this point, we started to evaluate the grids in Karamba3D and to see the advantages of each grid design considering the fabrication and assembly processes, comparing to the references we had collected before. This process took place with assisted development, with weekly remote meetings between the first author and the LAMO-PROURB students: Luca Rédua, Maria Eduarda Babo, Ronaldo Lee and Vinícius Salles. Together, we proceeded through the different stages, analysed the results and then advanced to the next stage. From the final solutions, we selected a surface from each student and 4 candidate grids, improving the solutions during our meetings. (Figure 6). 
Figure 6. Post-workshop research solutions, proposals

by Maria Eduarda Babo, Vinícius Salles, Ronaldo Lee and Luca Rédua (top to bottom). The proposals have several types of grid for each surface, tested in Karamba.

Source: authors / LAMOPROURB.
Figure 7. Displacement analysis with Karamba, values between 0.021 and $0.065 \mathrm{~cm}$.

Source: authors / LAMOPROURB.
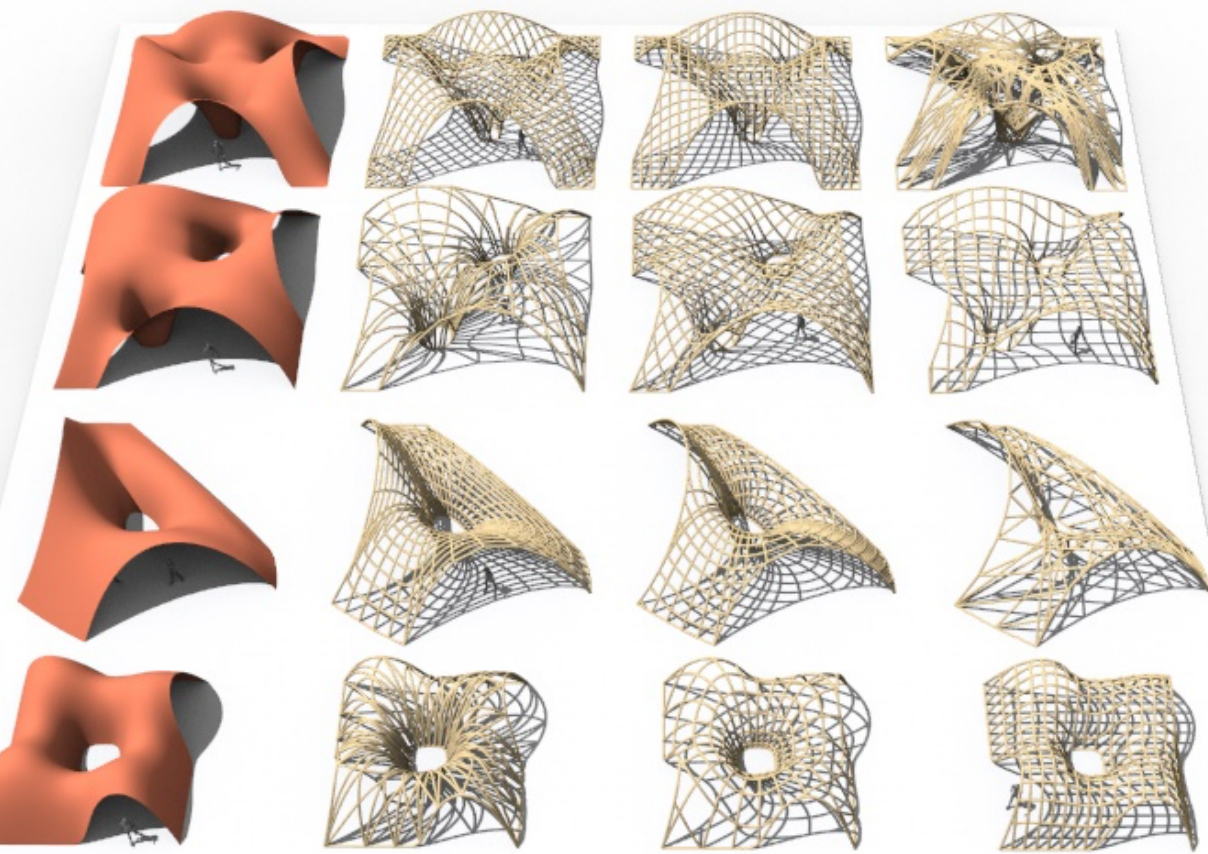

To develop the gridshells, we used informal knowledge through an empirical search for the best solutions for the geometry proposed by each researcher, which required successive tests in a feedback process. In this case, we are not talking about optimising in the strict mathematical sense, but exploring different geometric and constructive solutions, which, before facing these problems, we had not been able to foresee, neither the type of problem nor how to solve it. Solutions vary from geometry to geometry, from surface to surface. After choosing one geometry per researcher, we tested each grid with different dimensional parameters using Karamba3D, rejecting results outside the reference values. Finally, we carried out an in-depth analysis of the structural results. In the models, we considered generic material properties of wood, restricting the maximum curvature, and reflecting about the relationship between the candidate geometries, and their manufacturing and assembly processes. The LAMO/PROURB research group intends to start a construction process with physical models as soon as the laboratory restrictions related with the Covid pandemic are over, selecting the most interesting, feasible structures, developing the assembly process to build it full size. We recently introduced multi-criteria optimisation processes to find the best solutions using the plug-in Octopus.
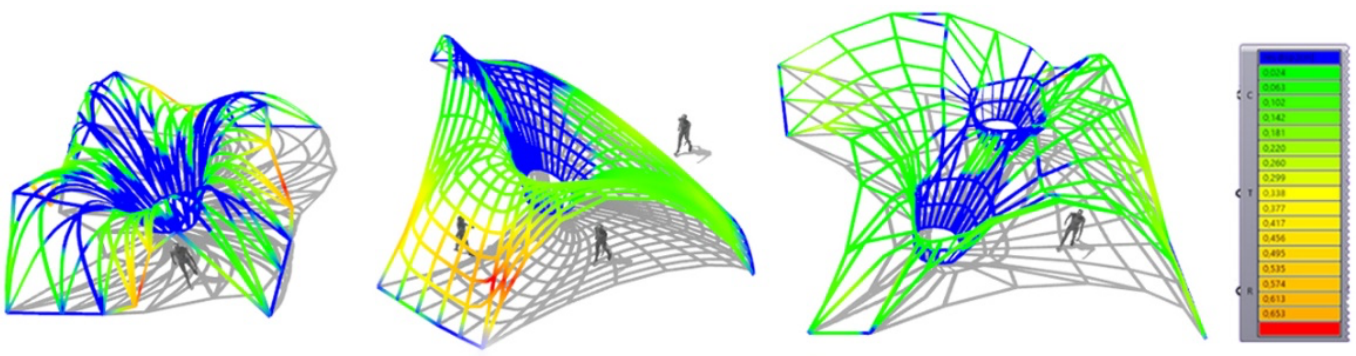


\section{RESULTS}

This article summarises the results of a progressive empirical-theoretical, applied to the study of gridshells, in which we sought to integrate the formal / informal knowledge and processes to develop architectural structures, seeking to introduce innovation, not only in their geometry, but also in the process.

This article discusses a sequence of projects and experiments, most of which are covered in intensive workshops, along with further extended research. This sequence of events provides feedback to a research system: for example, The Tropical Gridshell allowed identification of a problem in the development of structures that should include a structural study from the very first steps. This problem also allowed us to analyse different construction processes, looking for specific solutions. These processes studied theoretically or by analysing other examples, can only really be apprehended when building new physical solutions. In turn, when we built these proposals in workshops, this would required subsequent development of improved generative methods and systems with further experience in structural calculation. This allowed approaching surface designs with discontinuities, which we had avoided previously. In order to have synergy between materials and processes, this synchrony depends on a long process with several stages.

This joint development of architecture and structural engineering also highlights the differences between the methods used by the two disciplines. In structural engineering, it is more common to start from a problem to determine a goal, and then look for the right tools to solve that problem. This type of procedure then allows extending the solution to similar problems. On the other hand, in architecture, through experimentation, it is possible to see the possibilities and limitations in a vast field, in which, through exploratory experiments, we might define the tools and the method itself. Thus, one discipline values a precise focus, while the other adopts a broader search, considering multiple inputs, tending to use more exploratory thinking. According to a reference in Design Thinking as a broader engineering method, the processes tend to be pre-defined in order to be generalisable, while, in architecture, the processes are discovered by doing. According to a reference in Design Thinking (Tim Brown, 2017), creative designers first tend to diverge and generate multiple solutions, creating options, and then making choices, which allow solutions to converge to develop a proposal. During this experience, we learned a way to combine the strategies from both disciplines, in different stages to foster joint evolution.

In this sense, the research described seeks to integrate the tools of structural analysis creatively to find different families of solutions, developing a proto-method, which, in a certain way, requires deepened computational methods, but also deepens theoretical knowledge and the properties of materials. In short, it is a wider research that evolves by cumulative approaches in a feedback loop.

\section{ACKNOWLEDGMENTS}

The authors would like to thank all the participants in the various experiments, remembering that "construction" is a collective act to face challenges. In particular, we are grateful for their creation of Karamba3D and for granting licenses for the students to use it during the workshop.

We acknowledge the participation of all those in the workshops and the research group, especially in the seminars / workshops: 1 - GEODESIC CURVES, Generation and Construction, co-ordination Andres Passaro, with Clarice Rohde and Nicolle Prado, Nov 2016. 2- TROPICAL GRIDSHELL EXPERIENCE. FAU-UFRJ, 5th to 12th March 2018. Coordination: Gonçalo Castro Henriques (FAU-UFRJ / LAMO-PROURB) and Tobias Wallisser (ABK Stuttgart / LAVA) with 
Daniel Lenz, Felipe Tavares. Support: BRAGFOST Connect Program, Alexander Von Humboldt Foundation, DAAD, UFRJ, ABK Stuttgart / LAVA, FAPERJ and CNPq. 3 - OCA Traditional Brazilian Construction Reinvented, ABK Stuttgart, Oct. 2018. Coordination: Tobias Wallisser (ABK Stuttgart / LAVA) and Gonçalo Castro Henriques (FAU-UFRJ / LAMO-PROURB), with: Daniel Lenz, Sebastian Schott and Arnold Walz (Design to Production). 4 - MUTABLE SURFACES, 9th to 17th Feb. 2020. Partnership UFRJ, LAMO-PROURB, BIO-BIO (Chile), FADUUNL (Argentina) and UCR (Costa Rica). Co-ordination: Gonçalo Castro Henriques, Andres Passaro, Pedro Engel and Daniel Lenz, LAMO-PROURB. Invited partners: Rodrigo Garcia Alvarado and Mauro Chiarella, with Alexis Salinas, Paula Ulloa (Bio-Bio), Carla Tortul (FADUUNL), Juarez Franco (COPPE / UFRRJ), and Carolina Vargas (UCR).

\section{Referências Bibliográficas}

ADRIAENSSENS, Sigrid; BLOCK, Philippe; VEENENDAAL, Diederik; et al. Shell structures for architecture: Form

finding and optimization. 1. ed. London: Routledge, 2014. Disponível em:

https://www.taylorfrancis.com/books/e/9781315849270.

ALEXANDER, Christopher. Notes on Synthesis of Form. 7. ed. Cambridge: Harvard, University Press, 1973.

BROWN, Tim. Design Thinking: Uma metodologia poderosa para decretar o fim das velhas ideias. 1. ed. Rio de Janeiro: Alta Books, 2017.

BUCHANAN, Richard. Wicked Problems in Design Thinking. Design Issues, v. 8, p. 5-21, 2006. Disponível em: http://web.mit.edu/jrankin/www/engin_as_lib_art/Design_thinking.pdf.

CABRINHA, Mark N. Lattice shell methodologies. In: N. GU; S. WATANABE; H. ERHAN; et al (Orgs.). Proceedings 19th CAADRIA Conference Rethinking Comprehensive Design: Speculative Counterculture - . Hong Kong: The Association for Computer-Aided Architectural Design Research in Asia (CAADRIA), 2014, p. 191-200.

Disponível em: http://papers.cumincad.org/data/works/att/caadria2014_201.content.pdf.

CHAREST, Philippe; POTVIN, André; DEMERS, Claude M.H.; et al. Assessing the complexity of timber gridshells in architecture through shape, structure, and material classification. BioResources, v. 14, n. 1, 2019.

CHIARELLA, Mauro; GRONDA, Luciana; VEIZAGA, Martín. RILAB - architectural envelopes From spatial representation (generative algorithm) to geometric physical optimization (scientific modeling). In: SOUSA, José Pedro; HENRIQUES, Goncalo Castro; XAVIER, João Pedro (Orgs.). Architecture in the Age of the 4th Industrial Revolution - Proceedings of the 37th eCAADe and 23rd SIGraDi Conference. Porto: SIGraDi eCAADe, Blucher, 2019, v. 3, p. 17-24. Disponível em: http://papers.cumincad.org/data/works/att/ecaadesigradi2019_249.pdf.

D'AMICO, Bernardino; KERMANI, Abdy; ZHANG, Hexin. Form finding and structural analysis of actively bent timber grid shells. Engineering Structures, Elsevier, v. 81, p. 195-207, 2014. Disponível em: www.sciencedirect.com/science/article/pii/S014102961400580X.

FERNANDES, Jorge G.; KIRKEGAARD, Poul H.; BRANCO, Jorge M. Tectonic Design of Elastic Timber Gridshells. In: EBERHARDSTEINER, Josef; WINTER, Wolfgang; FADAl, Alireza; et al (Orgs.). World Conference on Timber Engineering WCTE 2016. Wien: TU Verlag Wien, 2016, p. 3155-3164. Disponível em: http://repositum.tuwien.ac.at/obvutwoa/content/titleinfo/1528439.

GONZALEZ QUINTIAL, Francisco; MARTÍN-PASTOR, Andrés. Convolutas Developable strips and digital fabricated lightweight architecture. In: SOUSA, José Pedro; HENRIQUES, Gonçalo Castro; XAVIER, João Pedro (Orgs.). Architecture in the Age of the 4th Industrial Revolution - Proceedings of the 37th eCAADe and 23rd SIGraDi Conference. Porto: eCAADe SIGraDi https://www.researchgate.net/publication/335703347, 2019, p. 585-93.

HARDING, John; PEARSON, Will; LEWIS, Harri; et al. The Ongreening Pavilion. In: Advances in Architectural Geometry 2014: Springer International Publishing, 2015, p. 295-308. Disponível em: https://link.springer.com/chapter/10.1007\%2F978-3-319-11418-7_19. 
HENRIQUES, Gonçalo Castro; FRANCO, Juarez Moara. Gridshells: integrating design with structural performance: formal and informal form finding. In: TORREBLANCA, Andres; ESCOBAR, Natalia Builes (Orgs.). Proceedings XXIV SIGraDi - Transformative Design. Medellin: SIGraDi / Blucher, 2020, p. 166-173. Disponível em: http://cumincad.scix.net/data/works/att/sigradi2020_23.pdf.

LIENHARD, Julian; ALPERMANN, Holger; GENGNAGEL, Christoph; et al. Active bending, a review on structures where bending is used as a self-formation process. International Journal of Space Structures, v. 28, n. 3-4, p. 187-196, 2013.

MITCHELL, William John; CELANI, Gabriela. A lógica da arquitetura: projeto, computação e cognição. Campinas, SP: UNICAMP, 2008.

MORK, John Haddal; DYVIK, Steinar Hillers $\varnothing$ y; MANUM, Bendik; et al. Introducing the segment lath - A simplified modular timber gridshell built in Trondheim Norway. In: WINTER, Wolfgang; EBERHARDSTEINER, Josef; JOURDA, Francoise-Hélène (Orgs.). WCTE 2016 - World Conference on Timber Engineering. Vienna: Verlag, 2016, p. 1-8. Disponível em: https://wcte2016.conf.tuwien.ac.at/home.

NABONI, Roberto. Form-finding to fabrication of super-thin anisotropic gridshell. In: MARTIN, Rodrigo; GRANERO, Adriana (Orgs.). Proceedings XX SIGraDi Congress of Iberoamerican Society Digital Graphics. Buenos Aires: SIGraDi, Blucher, 2016, p. 418-425.

NAICU, Dragos. Geometry and Performance of Timber Gridshells (MPhil Thesis). University of Bath, 2012. Disponível em: www.researchgate.net/publication/261860250.

PIKER, Daniel. Kangaroo: Form finding with computational physics. Architectural Design, v. 83, n. 2, p. 136137, 2013.PREISINGER, Clemens. Linking structure and parametric geometry. Architectural Design, v. 83, n. 2, p. 110-113, 2013.

QUINN, Gregory; GENGNAGEL, Christoph. A review of elastic grid shells, their erection methods and the potential use of pneumatic formwork. In: TEMMERMAN; BREBBIA (Orgs.). WIT Transactions on the Built Environment. Ostend, Belgium: WIT Press, 2014, v. 136, p. 129-143. Disponível em: www.researchgate.net/publication/264779291.

SEMPER, Gottfried. Style in the Technical and Tectonic Arts; or, Practical Aesthetics. Los Angeles: Getty Research Institute, 2004.

SORIANO, Enrique. Low-tech geodesic gridshell: Almond pavilion. ArchiDOCT, v. 4, n. 2, p. 29-38, 2017. Disponível em: www.enhsa.net/archidoct/Issues/vol4_iss2/ArchiDoct_vol4_iss2 02 Low-Tech Geodesic Gridshell Soriano.pdf.

TAYEB, F.; CARON, J. F.; BAVEREL, O.; et al. Stability and robustness of a $300 \mathrm{~m}^{2}$ composite gridshell structure. Construction and Building Materials, v. 49, p. 926-938, 2013.TOUSSAINT, M.H. A Design Tool for Timber Gridshells, The Development of a Grid Generation Tool, MSc Thesis. Delft University of Technology, 2007.

WALLISSER, Tobias; HENRIQUES, Goncalo Castro; RIBEIRO, Amanda; et al. Weaving physical-digital networks: Brazil-Germany integration experience. In: JOSÉ PEDRO, Sousa; GONCALO CASTRO, Henriques; JOÃO PEDRO, Xavier (Orgs.). Architecture in the Age of the 4th Industrial Revolution - Proceedings of the 37th eCAADe and 23rd SIGraDi Conference. Porto: José Pedro, Sousa Goncalo Castro, Henriques João Pedro, Xavier, 2019, v. 1, p. 315-324. Disponível em: http://papers.cumincad.org/data/works/att/ecaadesigradi2019_103.pdf.

YUAN, Philip F.; CHAI, Hua; JIN, Jinxi. Digital form-finding and fabrication of strained gridshells with complex geometries. In: WEIGUO XU (Org.). 23rd International Conference Computer-Aided Architectural Design Research in Asia: Learning, Prototyping and Adapting. Beijing: CAADRIA, 2018, v. 1, p. 267-276. Disponível em: http://papers.cumincad.org/data/works/att/caadria2018_165.pdf.

Gonçalo Castro Henriques gch@fau.ufri.br

Juarez Moara Franco juarezfranco@ufrrj.br 